\title{
FORUM
}

\section{Recommended Routes for Ships in Congested Waters}

\author{
from Captain J. García-Frías
}

Captain A. F. Dickson's paper entitled 'Recommended Routes for Ships in Congested Waters' (Journal, 17, 217) suggests the introduction of a principle which I advocated in two previous papers, 1,2 the second of which was presented at the Conferenza Internazionale Sulla Disciplina dell 'uso del Radar, in Genoa, May 1957. Captain Dickson writes in his article:

It is therefore suggested that the measures to be taken should involve the application of one simple basic rule, that in all cases ships should keep to the starboard side of any channel and that traffic rounding a headland should be separated so that ships proceeding in opposite directions will have a port-to-port passing. In addition, wherever possible the different streams of traffic should be separated by a lane which would be a virtual no-man's-land between ships sailing in opposite directions. The lane might well be shown in colour and British Admiralty experience seems to indicate that purple is a good colour for chart usage, so the lane might be known as the "purple lane".

In my works 1,2 it was stated 'Coastal radar navigation constitutes a very valuable means of making feasible an ordering of the natural traffic streams by regulating them according to the requirements of each area, following experience.

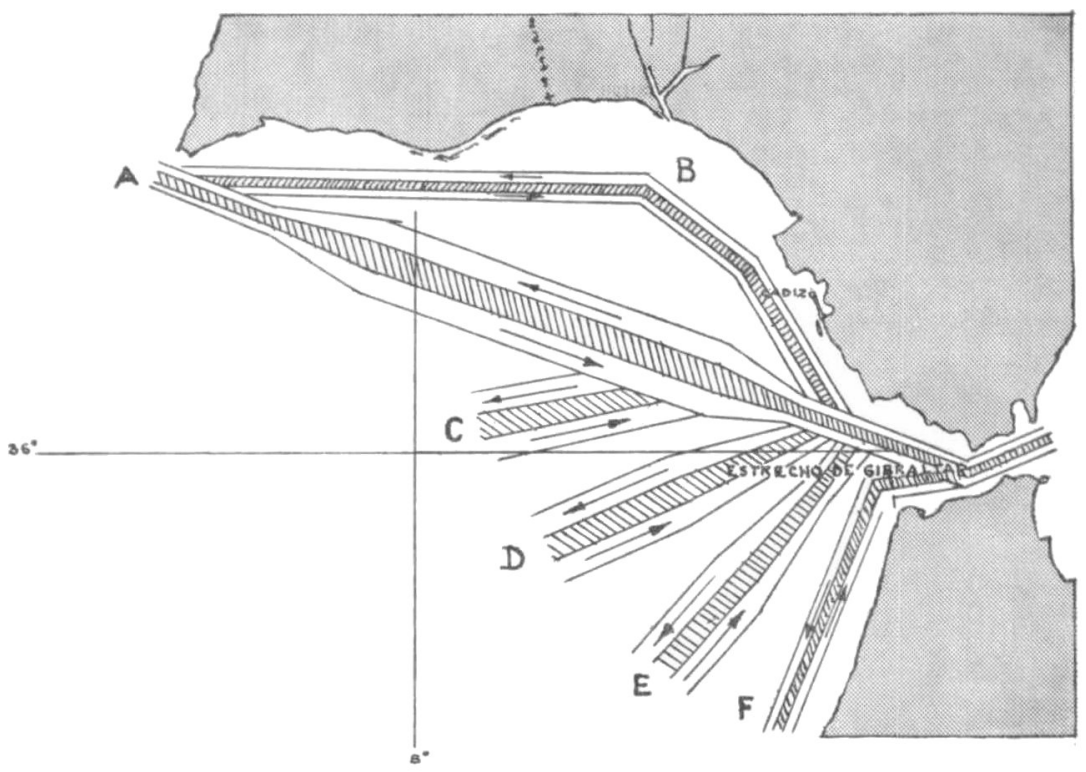

FIG. I 
As an example of the regulation of sea traffic in fog, an illustration corresponding to the western approach of the Strait of Gibraltar is shown.' And: "All incoming and outgoing streams through this area have been embodied into six triple lanes, each being made up of two lanes of opposing directions and by a neutral lane between them.'

Comparing this drawing in so far as it concerns the regulation of traffic in the Strait of Gibraltar with Fig. 2 of Captain Dickson's paper, the only difference between them lies in the width of the lanes.

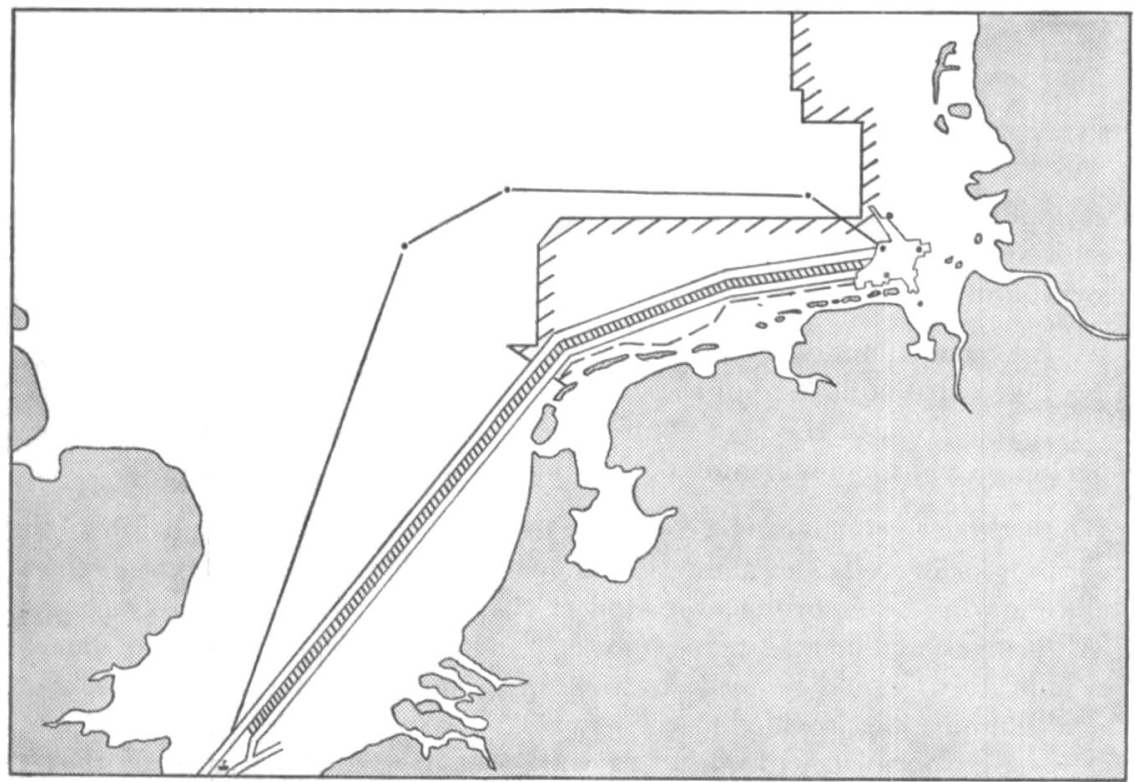

FIG. 2

Another interesting comparison-showing an unquestionable identity in the ideas involved in both drawings-is with Fig. 3 of Captain Solnnke's paper in the next number of the Journal $(17,389)$. In the explanation (p. 390) it is stated that the northern side of the 2-mile wide 'blue line' would mark the southern boundary of the 3-mile wide recommended track for westbound ships. It can be seen that the neutral lane is formed by 'widening' Oudet's 'blue line', whose original version ${ }^{3}$ coincides with the aim of my own suggestion-made three years earlier-in the sense of separating opposing traffic areas.

In the Naviroute proposed by Captain Robichon in 1958 in Navigation (The Journal of the French Institute of Navigation) is also presented 'a prohibited lane of a given width (varying with the precision of navigation required) separating the two opposed streams of traffic'. In my proposition ${ }^{1}$ published two years earlier, this same principle could be seen in the regulation shown for the area extending between the Strait of Gibraltar and Cape St. Vincent.

\section{REFERENCES}

1 García-Frías, J. (1956). Sobre un reglamento del uso del radar para prevenir los abordajes en la mar en tiempo de niebla, Revista General de Marina, March 1956. 
2 García-Frías, J. (1957). Sobre la posibilidad y realización de una reglamentación del uso del radar con visibilidad restringida para prevenir los abordajes en la mar. (This paper was presented at the 'Conferenza Internazionale Sulla Disciplina dell 'uso del radar', Genoa, May 1 957 , and published by the 'Civico Istituto Colombiano'.)

3 Oudet, L. (1959). Journal de la Marine Marchand, September.

\section{Bridge Lighting \\ from C. J. Roberts}

THE fundamental necessities of efficient bridge and chartroom lighting, which matter appears to have been ignored even on many of the latest vessels, are the provision of:

1. Adequate illumination of all instruments in a uniform manner.

2. Efficient illumination of the chart.

3. A reduction of the high contrast of light values between chartroom and wheelhouse and the elimination of the sources of glare.

These three essentials can be combined to render the overall illumination of the navigating bridge efficient and practical, whether the ship has a separate chartroom and wheelhouse or the more modern chartroom and wheelhouse combined.

All bridge instruments, such as clocks, compasses, telegraphs and the numerous indicators, should be made to a uniform specification-all with 'back' or 'edge' illumination provided by red lamps. Where practicable these instruments should have black dials with white lettering. An extra refinement is to have the lettering painted with a luminous paint. llluminating the instruments in this manner would also afford a certain amount of illumination to the otherwise dark navigating position. This would in turn tend to alleviate the high contrast of light between the chart area, which of necessity must be lit, and the total darkness outside.

A great reduction in the
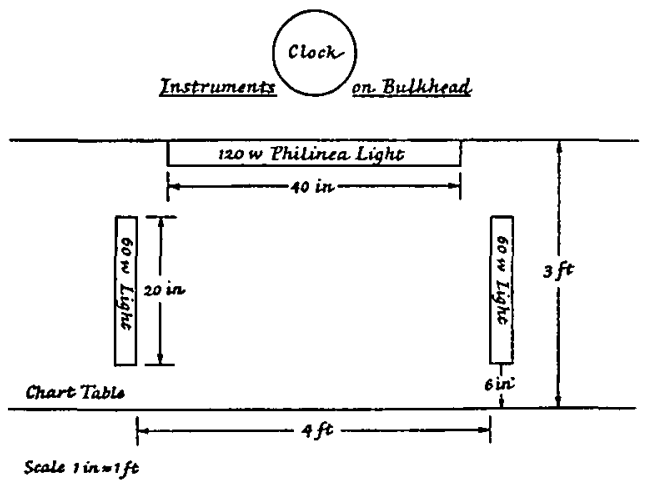

FIG. I. Arrangement of lights contrasting light intensities would be achieved by employing red shaded strip lighting to illuminate the chart. Strip lights provided with means for dimming will afford an adequate and efficient method of lighting the chart for all working conditions and would help to bring all the bridge lighting to a more common level. Shaded strip lights would also avoid most, if not all the glare experienced

with present conventional methods of chart lighting. 